\title{
Electric Vehicle Preparedness: \\ Task 2, Identification of Vehicles for Installation of Data Loggers for Marine Corps Base Camp Lejeune
}

Stephen Schey

Jim Francfort

February 2015

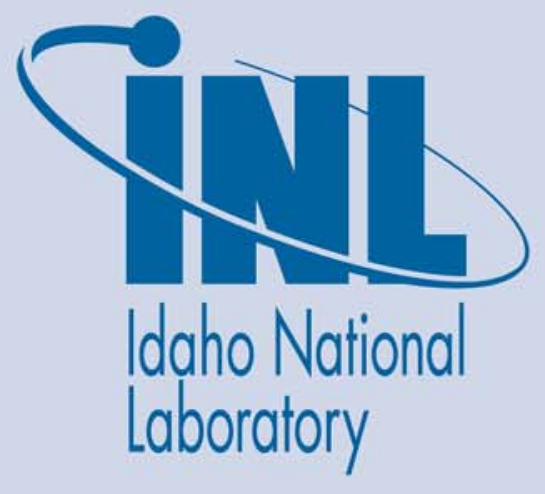

The INL is a U.S. Department of Energy National Laboratory operated by Battelle Energy Alliance 
INL/EXT-15-34744

\title{
Electric Vehicle Preparedness: Task 1, Identification of Vehicles for Installation of Data Loggers for Marine Corps Base Camp Lejeune
}

\author{
Stephen Schey \\ Jim Francfort \\ Stephen Schey, Project Manager, Infrastructure Planning and Analysis, Intertek Testing Services, \\ Jim Francfort, Vehicle Systems Principal Investigator, Idaho National Laboratory operated by \\ Battelle Energy Alliance, Idaho Falls, ID
}

February 2015

Idaho National Laboratory

Idaho Falls, Idaho 83415

http://avt.inl.gov

Prepared for the

U.S. Department of Energy

Office of Nuclear Energy

Under DOE Idaho Operations Office

Contract DE-AC07-05ID14517 


\section{DISCLAIMER}

This information was prepared as an account of work sponsored by an agency of the U.S. Government. Neither the U.S. Government nor any agency thereof, nor any of their employees, makes any warranty, expressed or implied, or assumes any legal liability or responsibility for the accuracy, completeness, or usefulness, of any information, apparatus, product, or process disclosed, or represents that its use would not infringe privately owned rights. References herein to any specific commercial product, process, or service by trade name, trade mark, manufacturer, or otherwise, does not necessarily constitute or imply its endorsement, recommendation, or favoring by the U.S. Government or any agency thereof. The views and opinions of authors expressed herein do not necessarily state or reflect those of the U.S. Government or any agency thereof. 


\section{ABSTRACT}

Battelle Energy Alliance, LLC, managing and operating contractor for the U.S. Department of Energy's Idaho National Laboratory, is the lead laboratory for the U.S. Department of Energy's advanced vehicle testing. Battelle Energy Alliance, LLC contracted with Intertek Testing Services, North America (Intertek) to conduct several U.S. Department of Defense-based studies to identify potential U.S. Department of Defense transportation systems that are strong candidates for introduction or expansion of plug-in electric vehicles (PEVs).

In Task 1, a survey was completed of the inventory of non-tactical fleet vehicles at the Marine Corps Base Camp Lejeune (MCBCL) to characterize the fleet. This information and characterization was used to select vehicles for further monitoring, which involves data logging of vehicle movements in order to identify the vehicle's mission and travel requirements. Individual observations of these selected vehicles provide the basis for recommendations related to PEV adoption. It also identifies whether a battery electric vehicle or plug-in hybrid electric vehicle (collectively referred to as PEVs) can fulfill the mission requirements and provides observations related to placement of PEV charging infrastructure.

This report provides the list of vehicles selected by MCBCL and Intertek for further monitoring and fulfills the Task 2 requirements.

Intertek acknowledges the support of Idaho National Laboratory and MCBCL fleet management and personnel for participation in this study.

Intertek is pleased to provide this report and is encouraged by the enthusiasm and support from MCBCL personnel. 


\section{EXECUTIVE SUMMARY}

Federal agencies are mandated ${ }^{a}$ to purchase alternative fuel vehicles, increase consumption of alternative fuels, and reduce petroleum consumption. Available plug-in electric vehicles (PEVs) provide an attractive option in the selection of alternative fuel vehicles. PEVs, which consist of both battery electric vehicles and plug-in hybrid electric vehicles, have significant advantages over internal combustion engine vehicles in terms of energy efficiency, reduced petroleum consumption, and reduced production of greenhouse gas emissions, and they provide performance benefits with quieter, smoother operation. This study intended to evaluate the extent to which the Marine Corps Base Camp Lejeune (MCBCL) could convert part or all of their fleet of vehicles from petroleum-fueled vehicles to PEVs.

The Task 1 report provided an assessment of the existing non-tactical fleet of vehicles at MCBCL to characterize its current components. From this characterization, the 60 -vehicle subset of representative vehicles was selected for an in-depth assessment. This led to specific results for these selected vehicles and wider extrapolation to the full fleet of vehicles.

The MCBCL non-tactical fleet contains 862 vehicles for which counterpart PEVs are currently available or are expected to be available in the near future. Of the 862 vehicles, this report identifies the 60 -vehicle subset that has been selected for further monitoring and evaluation.

${ }^{\text {a }}$ Energy Policy act of 1992, Energy Policy Act of 2005, Executive Order 13423, and Energy Independence and Security Act of 2007. 


\section{CONTENTS}

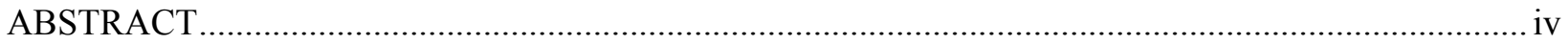

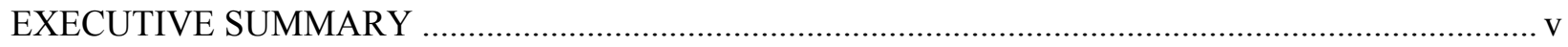

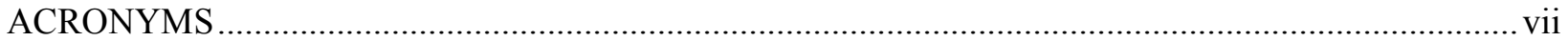

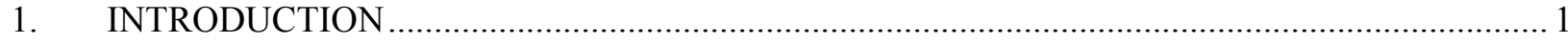

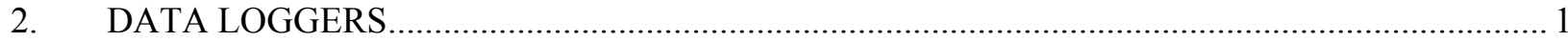

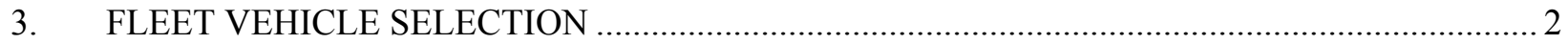

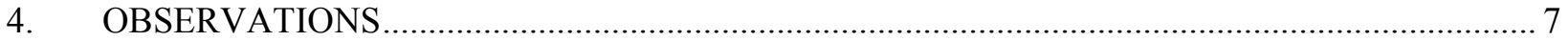

\section{FIGURES}

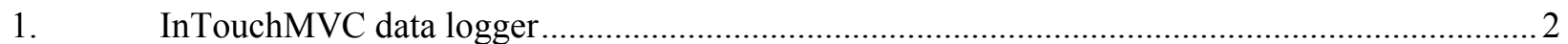

2. Vehicle type distribution for vehicles with data loggers ....................................................... 4

3. Model year distribution for vehicles with data loggers ..................................................... 5

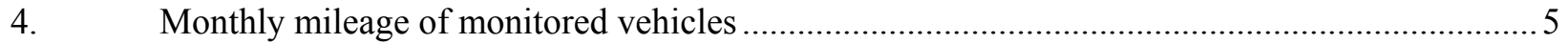

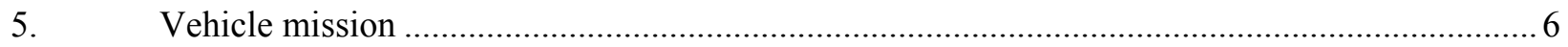

6. Monthly mileage distributions for monitored vehicles......................................................... 6

TABLES

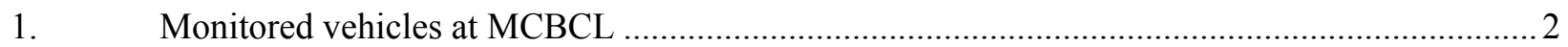

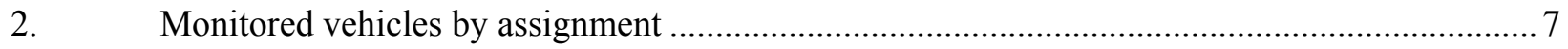




\section{ACRONYMS}

BEV battery electric vehicle

Intertek Intertek Testing Services, North America

MCBCL Marine Corps Base Camp Lejeune

MOU memorandum of understanding

PEV plug-in electric vehicle (includes BEVs and PHEVs, but not hybrid electric vehicles)

PHEV plug-in hybrid electric vehicle 


\section{Electric Vehicle Preparedness: Task 1, Identification of Vehicles for Installation of Data Loggers for Marine Corps Base Camp Lejeune}

\section{INTRODUCTION}

The U.S. Department of Energy and the U.S. Department of Defense signed a memorandum of understanding (MOU) on July 22, 2010, for strengthening the coordination of efforts to enhance national energy security and to demonstrate federal government leadership in transitioning the United States to a low-carbon economy. The MOU included efforts in the areas of energy efficiency, fossil fuels, alternative fuels, efficient transportation technologies and fueling infrastructure, grid security, smart grid, and energy storage.

In support of the MOU, Idaho National Laboratory, with funding provided by the U.S. Department of Energy's Vehicle Technologies Office and Federal Energy Management Program, directed Intertek Testing Services, North America (Intertek) to conduct several U.S. Department of Defense-based studies. These studies were conducted to identify potential transportation systems that are strong candidates for introduction or expansion of plug-in electric vehicles (PEVs). Intertek previously has conducted similar fleet, city, state, and countrywide studies using their EV Micro-Climate ${ }^{\circledR}$ assessment process, which consists of the following four main tasks:

- Task 1: Conduct a non-tactical vehicle fleet assessment

- Task 2: Identify vehicles for further mission and fleet characterizations

- Task 3: Perform detailed assessment of selected vehicles and charging infrastructure needs

- $\quad$ Task 4: Provide an implementation approach for adoption of electric vehicles.

An assessment of the potential for replacing the Marine Corps Base Camp Lejeune (MCBCL) fleet vehicles with PEVs starts with characterization of fleet vehicles' missions and vehicle characteristics. That assessment was presented in the Task 1 report: "Assessment of Fleet Inventory for Marine Corps Base Camp Lejeune."

PEVs generally are classified into two vehicle types: (1) battery electric vehicles (BEVs) and (2) plug-in hybrid electric vehicles (PHEVs). A BEV contains an onboard battery that provides all motive power. PHEVs also have an onboard battery that provides some motive power; however, there is another motive power source (such as a gasoline engine). Generally, PHEVs have a charge-depleting mode, where the battery provides all or most (depending on the PHEV design) of the motive power with the battery being depleted. They also have a charge-sustaining mode, where the non-battery power source provides the majority of the motive power while being supplemented by battery power and the battery state of charge is maintained within a designed range. A BEV can be considered to operate solely in charge-depleting mode. Collectively, BEVs and PHEVs are referred to as PEVs.

The Task 1 effort led to identification of fleet vehicles that appear to be good candidates for replacement by PEVs. To validate the survey results, 60 vehicles within the candidate groups are selected for further monitoring and analysis through addition of vehicle data loggers. The Task 2 results are presented in this document.

\section{DATA LOGGERS}

Individual privacy concerns exist when monitoring vehicle movement with data loggers. Data collection occurs by data logger number, vehicle identification number, or an agency-assigned vehicle number. Intertek receives no information related to the vehicle operator and provides no raw data to the fleet managers. In this manner, Intertek does not collect, analyze, or report on individual driving habits.

Data are collected using non-intrusive data loggers (Figure 1) that are placed into the vehicle's onboard diagnostic port. Installation of the data loggers and manual recording of information about the 
vehicle that ties the logger and vehicle together in the data, typically take less than 5 minutes and is completed by the fleet managers or designees. The data loggers transmit vehicle information through cellular means to a data center where Intertek retrieves this information. Once installed and activated during vehicle use, the data loggers transmit vehicle information every minute during vehicle operation by cellular communication to the data center.

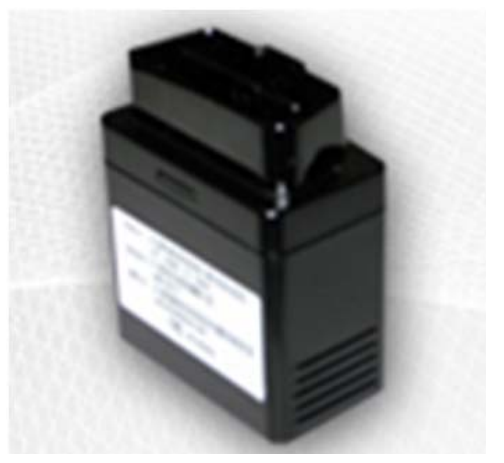

Figure 1. InTouchMVC data logger. ${ }^{2}$

Intertek maintains the data logger's connectivity and verifies data transmission weekly. Missing data (reported as "null" values) are frequently the result of lost global positioning system reception, logger device removal, or extended periods in regions with insufficient cellular reception. Intertek filters the vehicle and data logger information if these null values present a significant impact on the data collected and no resolution is possible.

Data consist of key-on events, key-off events, and position updates logged every minute while the vehicle is keyed-on. InTouchMVC fleet reporting converts these data points into records of trip events, stop events, and idle events.

From these data points, the following information will be available for evaluation:

- Trip start and stop time and location

- Trip distance and duration

- Idle start time, location, and duration

- Typical vehicle operating schedule.

The data loggers are retained on a vehicle for approximately 6 to 8 weeks to gather sufficient movement information on the vehicle.

\section{FLEET VEHICLE SELECTION}

The 60 vehicles selected by MCBCL and Intertek for further study are identified in Table 1.

Table 1. Monitored vehicles at MCBCL.

\begin{tabular}{|c|c|c|c|c|c|c|}
\hline $\begin{array}{c}\text { Fleet } \\
\text { Vehicle Id }\end{array}$ & Year & Make & Model & EPA Class & Odometer & $\begin{array}{c}\text { Estimated } \\
\text { Annual Miles }\end{array}$ \\
\hline 290597 & 1997 & Ford & E350 & Van - Cargo & 27,949 & 957 \\
\hline 290910 & 2003 & International & 4200 SBA & SP & 69,793 & 3,507 \\
\hline 291045 & 2006 & Ford & F550 & SP & 41,941 & 3,656 \\
\hline 291073 & 2007 & Ford & E250 & Van - Pass & 45,547 & 2,935 \\
\hline 294285 & 2009 & X & Malibu & Sedan - Midsize & 44,190 & 3,795 \\
\hline 294293 & 2009 & Chevrolet & HHR & SUV & 53,870 & 4,214 \\
\hline
\end{tabular}

\footnotetext{
${ }^{2}$ www.intouchmvc.com [accessed July 30, 2014]
} 


\begin{tabular}{|c|c|c|c|c|c|c|}
\hline $\begin{array}{c}\text { Fleet } \\
\text { Vehicle Id }\end{array}$ & Year & Make & Model & EPA Class & Odometer & $\begin{array}{c}\text { Estimated } \\
\text { Annual Miles }\end{array}$ \\
\hline 294315 & 2009 & Chevrolet & 3500 & Pickup & 23,997 & 3,208 \\
\hline 294324 & 2009 & Chevrolet & HHR & SUV & 42,589 & 8,195 \\
\hline 301321 & 2012 & Ford & F350 & Pickup & 11,849 & 3,669 \\
\hline 302039 & 2014 & Ford & F250XL & Pickup & 6,781 & 6,424 \\
\hline 302040 & 2014 & Ford & F250XL & Pickup & 13,083 & 10,937 \\
\hline 302334 & 2015 & Ford & F350 stake & Pickup & 6 & 1,200 \\
\hline G103327L & 2012 & Chevrolet & Malibu & Sedan - Midsize & 17,359 & 7,085 \\
\hline G130325K & 2012 & Ford & Focus & Sedan - Compact & 6,380 & 1,037 \\
\hline G137974P & 2015 & Ford & Focus & Sedan - Compact & 6,295 & 12,000 \\
\hline G410379H & 2009 & Dodge & Grd Caravan & Minivan & 25,874 & 5,614 \\
\hline G410391H & 2009 & Dodge & DAKOTA & Pickup & 27,140 & 7,507 \\
\hline G410754M & 2012 & Dodge & Grd Caravan & Minivan & 10,918 & 5,183 \\
\hline G410762M & 2012 & Dodge & Grd Caravan & Minivan & 24,992 & 20,099 \\
\hline G410806P & 2014 & Dodge & Grd Caravan & Minivan & 12,562 & 12,552 \\
\hline G411689L & 2011 & Ford & Ranger & Pickup & 18,215 & 5,649 \\
\hline G411846K & 2011 & Dodge & Grd Caravan & Minivan & 43,151 & 12,317 \\
\hline G412399K & 2010 & Dodge & Dakota & Pickup & 32,811 & 10,754 \\
\hline G413297K & 2011 & Ford & Ranger & Pickup & 18,013 & 5,368 \\
\hline G413300K & 2011 & Ford & Ranger & Pickup & 39,239 & 15,644 \\
\hline G413301K & 2011 & Ford & Ranger & Pickup & 21,645 & 7,306 \\
\hline G420216F & 2008 & Ford & E150 & Van - Pass & 16,356 & 2,189 \\
\hline G420644M & 2012 & Ford & E150 & Van - Pass & 42,887 & 22,209 \\
\hline G420667P & 2014 & Ford & F150 & Pickup & 6,576 & 9,600 \\
\hline G420671P & 2014 & Ford & F150 & Pickup & 7,688 & 7,678 \\
\hline G420883M & 2012 & Ford & E150 & Van - Pass & 42,763 & 16,827 \\
\hline G420898M & 2012 & Ford & E150 & Van - Pass & 36,465 & 16,246 \\
\hline G420911L & 2012 & Chevrolet & $\mathrm{C} 1500$ & Pickup & 20,898 & 7,978 \\
\hline G420915M & 2012 & Ford & F150 & Pickup & 16,287 & 7,072 \\
\hline G422985H & 2010 & Chevrolet & $\mathrm{C} 1500$ & Pickup & 63,594 & 20,146 \\
\hline G430310H & 2009 & Ford & E350 & Van - Pass & 55,280 & 7,232 \\
\hline G430323H & 2009 & Ford & E350 & Van - Cargo & 67,585 & 12,155 \\
\hline G430324H & 2009 & Ford & E350 & Van - Cargo & 32,035 & 5,969 \\
\hline G430326H & 2009 & Chevrolet & $2500 \mathrm{HD}$ & Pickup & 39,522 & 4,863 \\
\hline G431182M & 2012 & Chevrolet & CG3300 & Van - Cargo & 28,376 & 12,279 \\
\hline G431453G & 2008 & Chevrolet & G2300 & Van - Pass & 64,529 & 15,539 \\
\hline G431855P & 2015 & Ford & F350 & Pickup & 2,522 & 4,800 \\
\hline G432025K & 2010 & Ford & F250 & Pickup & 12,867 & 3,755 \\
\hline G434073F & 2008 & Chevrolet & G2300 & Van - Pass & 51,238 & 4,712 \\
\hline G434075P & 2015 & Ford & F250 & Pickup & 464 & 3,600 \\
\hline G610161H & 2009 & Dodge & Dakota & Pickup & 46,893 & 14,979 \\
\hline G610174H & 2009 & Jeep & Liberty & SUV & 38,149 & 8,683 \\
\hline G610594L & 2011 & Jeep & Patriot & SUV & 26,107 & 10,657 \\
\hline G610879P & 2014 & Chevrolet & Equinox & SUV & 4,434 & 4,232 \\
\hline G611508D & 2008 & Jeep & Liberty & SUV & 31,152 & 1,051 \\
\hline
\end{tabular}




\begin{tabular}{|c|c|c|c|c|c|c|}
\hline $\begin{array}{c}\text { Fleet } \\
\text { Vehicle Id }\end{array}$ & Year & Make & Model & EPA Class & Odometer & $\begin{array}{c}\text { Estimated } \\
\text { Annual Miles }\end{array}$ \\
\hline G611509D & 2008 & Jeep & Liberty & SUV & 26,551 & 3,292 \\
\hline G612644P & 2015 & Jeep & Patriot & SUV & 10 & 3,600 \\
\hline G620791H & 2009 & Ford & Expedition & SUV & 45,614 & 9,273 \\
\hline G621583G & 2008 & Chevrolet E & K1500 & Pickup & 60,381 & 10,816 \\
\hline G624085L & 2012 & Dodge & 1500 & Pickup & 17,386 & 10,608 \\
\hline G630163H & 2009 & Chevrolet & K2500HD & Pickup & 57,812 & 9,018 \\
\hline G630934G & 2008 & Chevrolet & K3500 & Pickup & 49,385 & 7,502 \\
\hline G632765D & 2007 & Dodge & 2500 & Pickup & 23,537 & 2,469 \\
\hline G632885L & 2012 & Chevrolet & K2500HD & Pickup & 10,474 & 4,112 \\
\hline G632888L & 2012 & Chevrolet & K2500HD & Pickup & 13,548 & 4,480 \\
\hline
\end{tabular}

Figure 2 shows the distribution of the vehicle types monitored. It also compares the percent of vehicles monitored against the entire inventory of vehicles. As can be seen in Figure 2, this distribution is approximately representative of the full fleet.

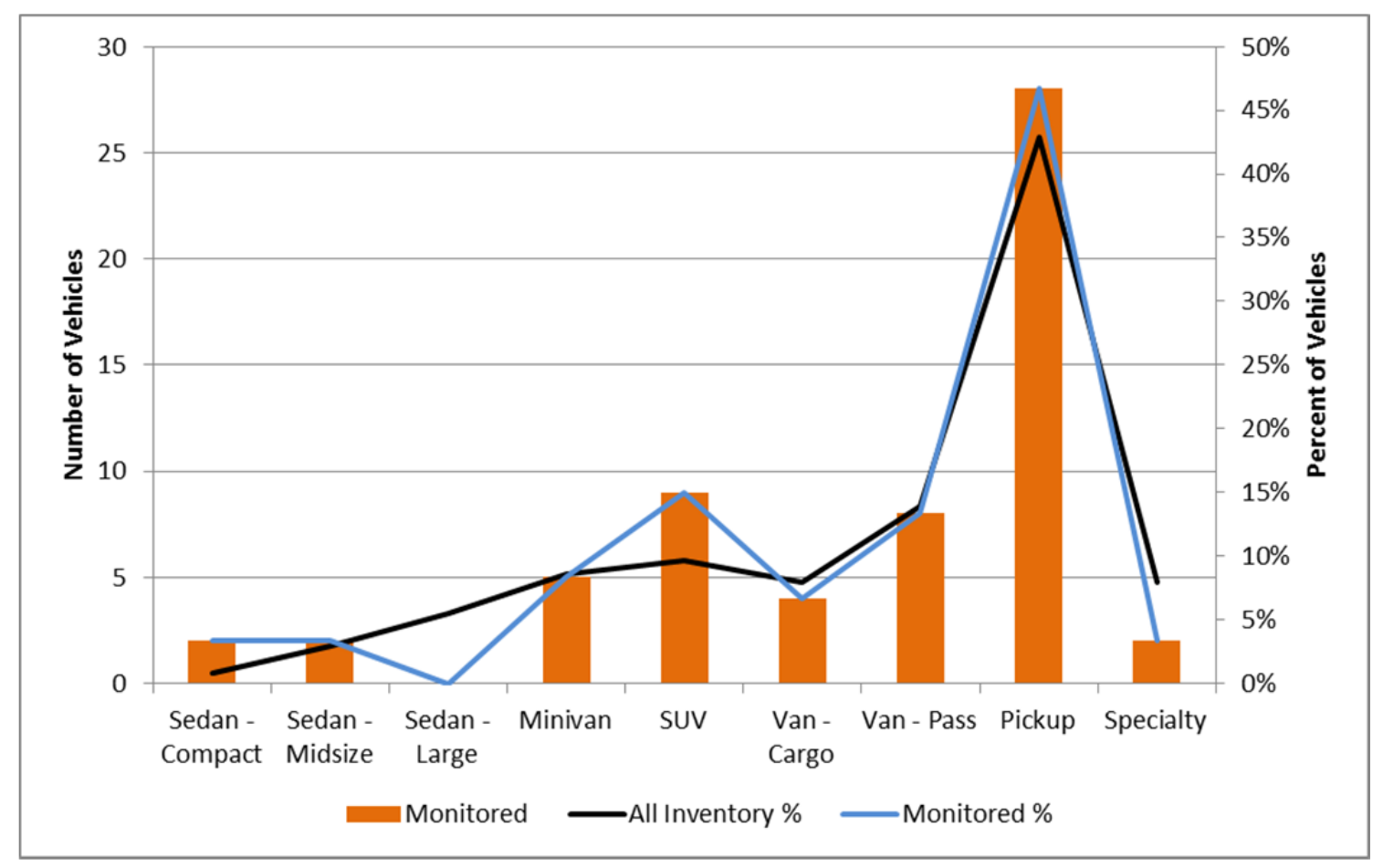

Figure 2. Vehicle type distribution for vehicles with data loggers.

Figure 3 provides the distributions for model year and compares them to the full inventory of vehicles. Again, the selected vehicles are representative of the full fleet. 


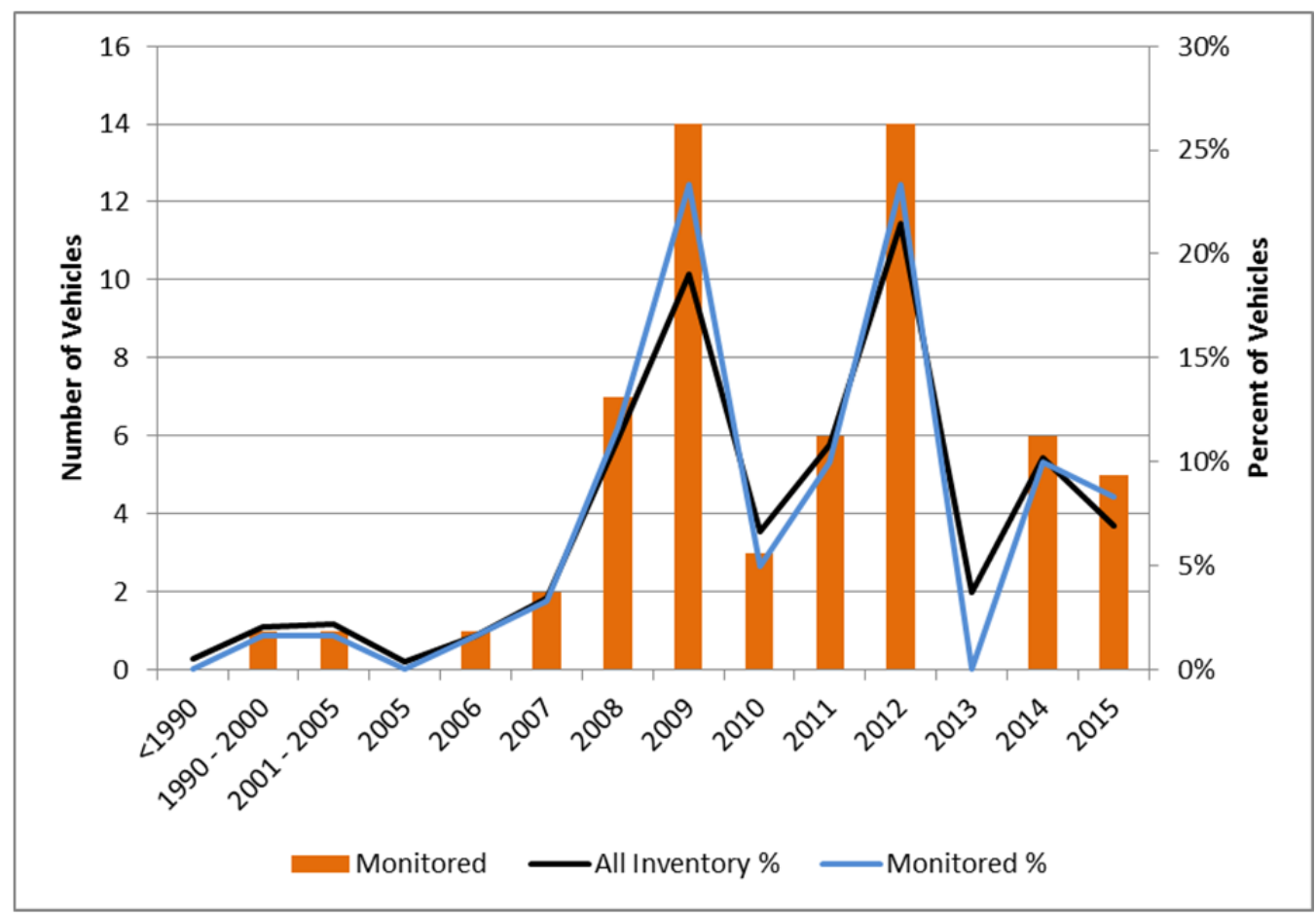

Figure 3. Model year distribution for vehicles with data loggers.

Figure 4 shows the monthly mileage of the monitored vehicles and compares it to the full inventory of vehicles. The characteristics of the monitored vehicles closely match the entire inventory.

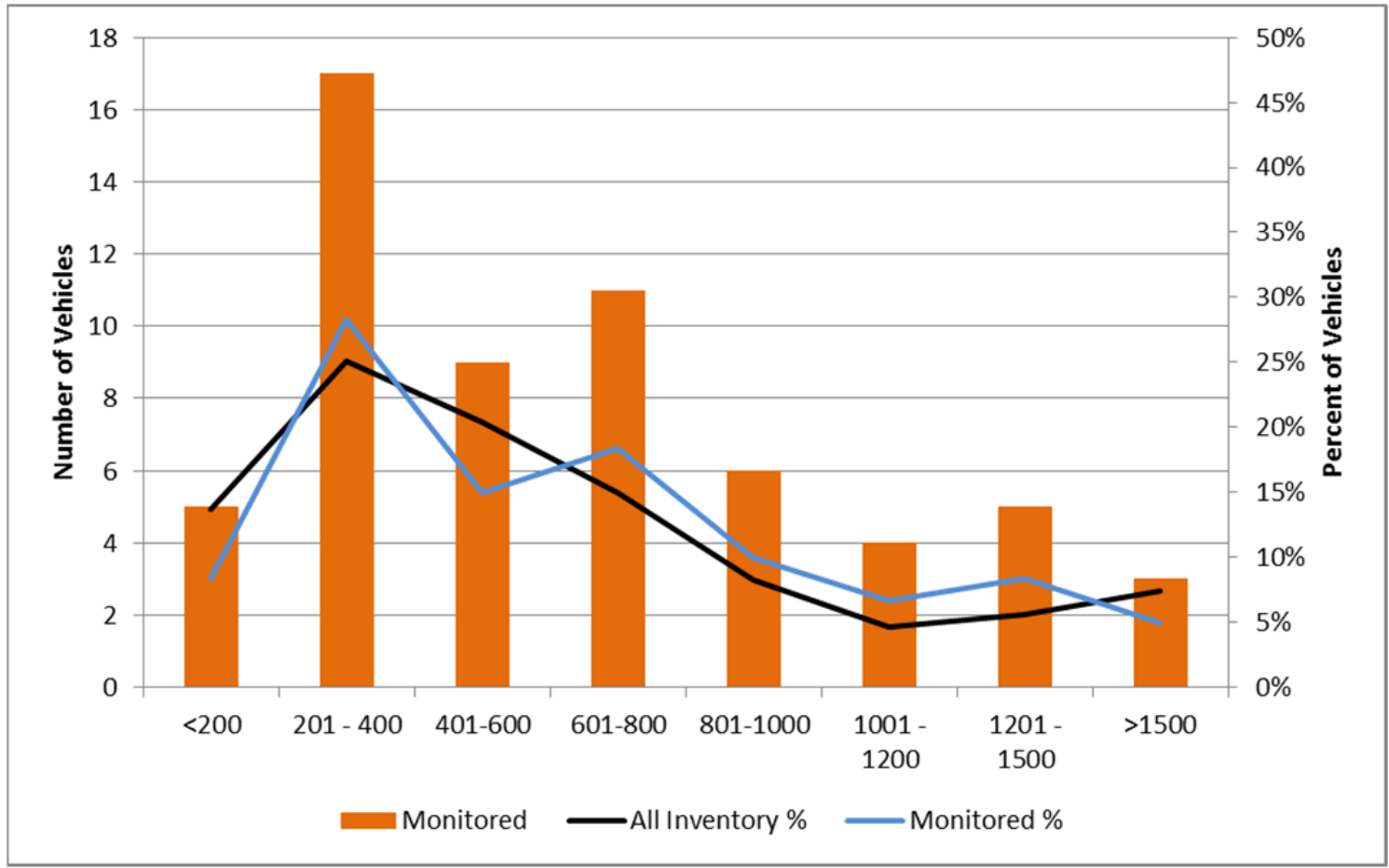

Figure 4. Monthly mileage of monitored vehicles.

Figure 5 identifies the mission of the selected vehicles compared to the mission of the full inventory. 


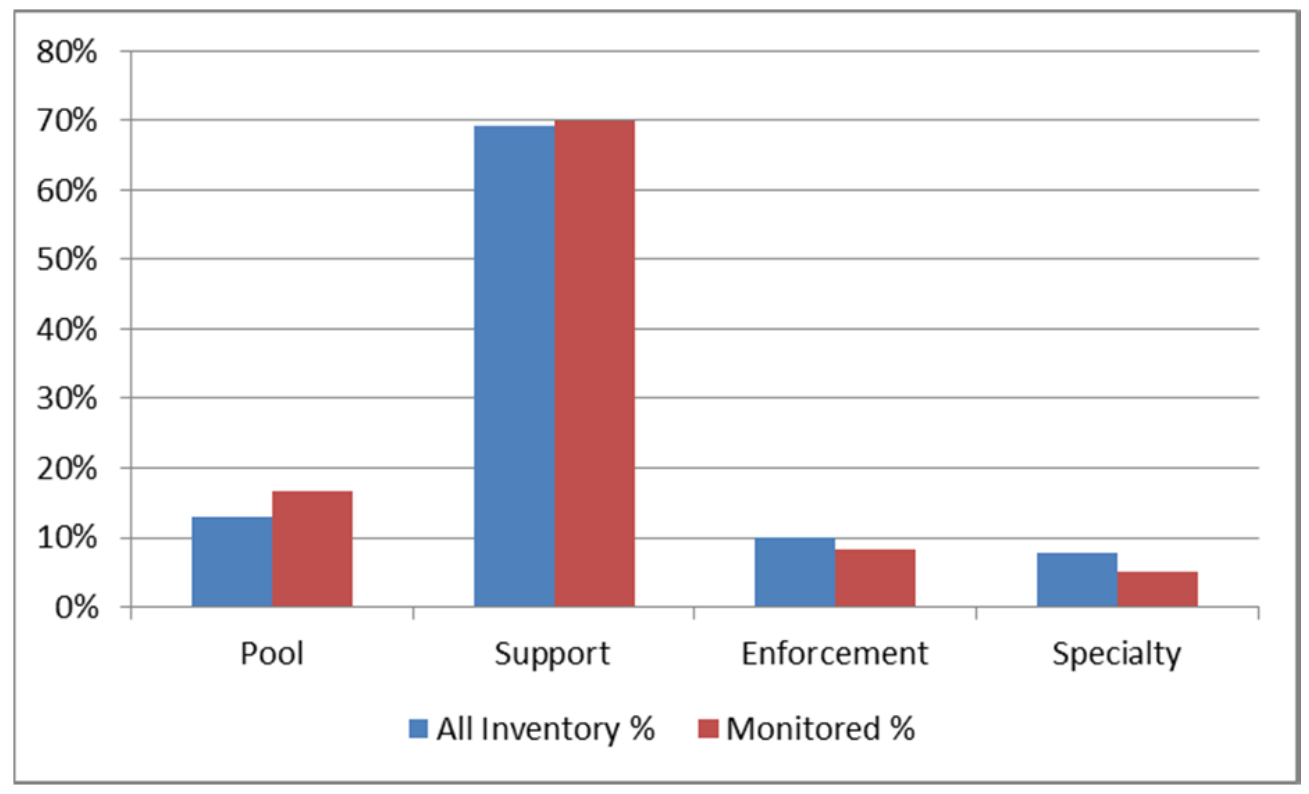

Figure 5. Vehicle mission.

Figure 6 presents the monthly mileage distribution of the vehicles selected for monitoring. If one assumes a battery range of 70 miles for a BEV and 21 working days per month, then a vehicle that consistently travels the same distance each day would have to travel greater than approximately 1,500 miles per month to exceed the battery's capacity. Fully $95 \%$ of the monitored vehicles average less than 1,500 miles per month in travel. This is nearly the same percentage as the entire fleet inventory. Therefore, barring charging constraints associated with the timing of daily mission activities, payload requirements, and range issues associated with off-base trips, a significant number of vehicles should be eligible for replacement by BEVs.

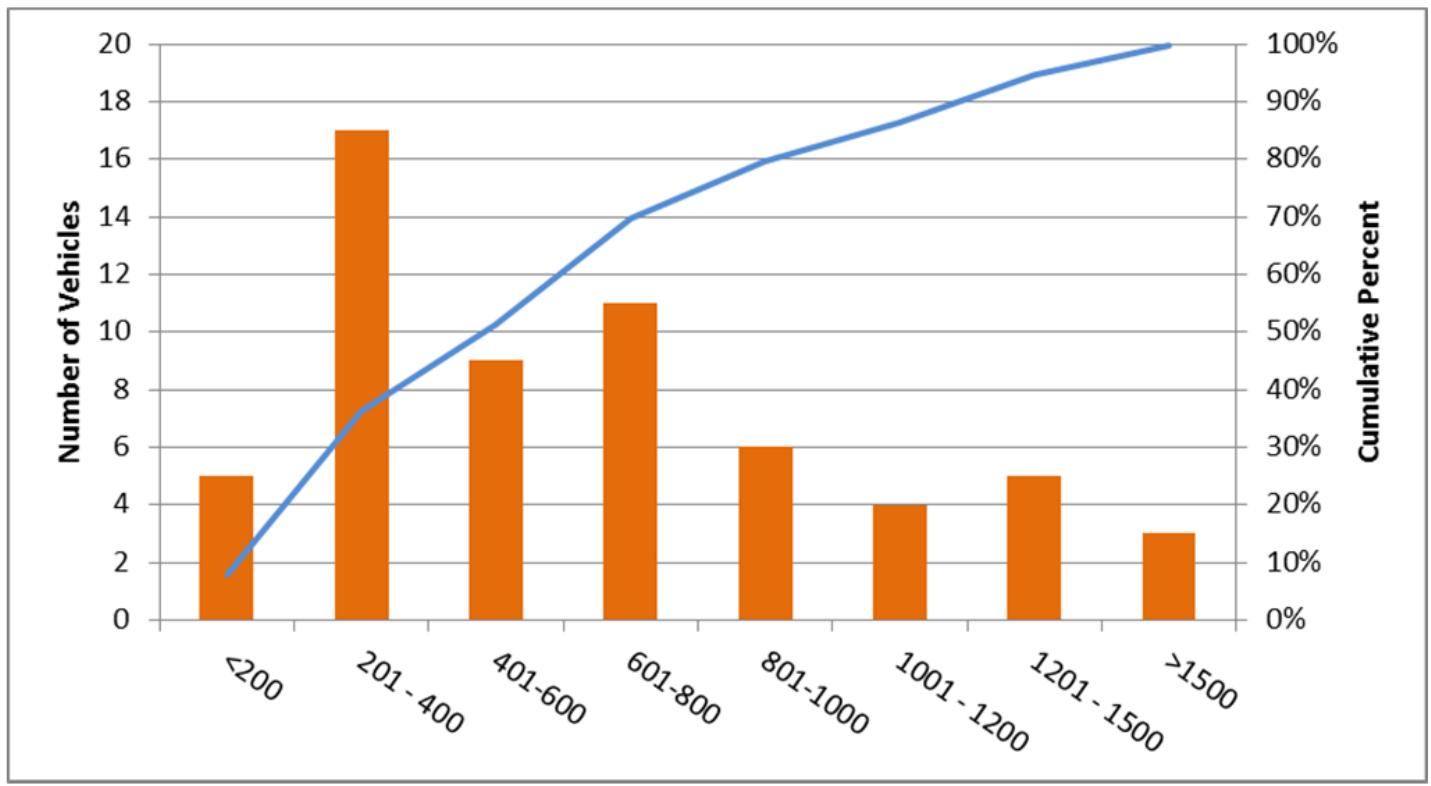

Figure 6. Monthly mileage distributions for monitored vehicles.

Finally, the Task 1 report identified the tenant commands and Marine Corps Installation East departments and divisions to which the vehicles are assigned. The monitored vehicles also represent a cross section of these tenant commands and Marine Corps Installation East departments (see Table 2). 
Table 2. Monitored vehicles by assignment.

\begin{tabular}{lcccccccccc}
\hline & $\begin{array}{c}\text { Sedan } \\
\text { Compact }\end{array}$ & $\begin{array}{c}\text { Sedan } \\
\text { Midsize }\end{array}$ & $\begin{array}{c}\text { Sedan } \\
\text { Large }\end{array}$ & Minivan & SUV & $\begin{array}{c}\text { Van } \\
\text { Cargo }\end{array}$ & $\begin{array}{c}\text { Van } \\
\text { Pass }\end{array}$ & Pickup & Specialty & Total \\
\hline $\begin{array}{l}\text { Tenant } \\
\text { Commands }\end{array}$ & 0 & 0 & 0 & 2 & 3 & 0 & 6 & 7 & 0 & 18 \\
$\begin{array}{l}\text { Marine Corps } \\
\text { Installation East }\end{array}$ & 2 & 2 & 0 & 3 & 6 & 4 & 2 & 21 & 2 & 42 \\
Total & 2 & 2 & 0 & 5 & 9 & 4 & 8 & 28 & 2 & 60 \\
\hline
\end{tabular}

\section{OBSERVATIONS}

The 60 -vehicle subset of the fleet inventory reflects the overall fleet inventory's characteristics. Data collection on these vehicles will commence and the results will be the focus of Task 3 . The close match of the monitored vehicles to the full fleet allows extrapolation of data on the 60 -vehicle subset to the full fleet. 